
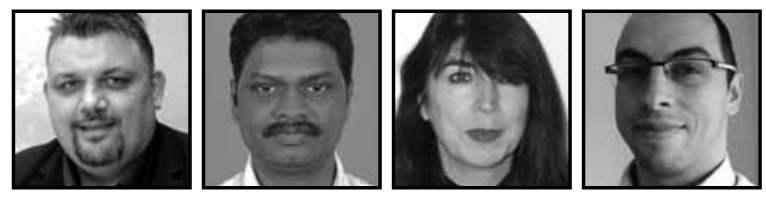

\title{
Enabling Creativity in Learning Environments: Lessons From the CREANOVA Project
}

\author{
John M. Davis, Vinnarasan Aruldoss, Lynn McNair, \\ and Nikolaos Bizas \\ University of Edinburgh
}

\section{ABSTRACT}

The paper employs data from a European Union funded project to outline the different contexts and factors that enable creativity and innovation. It suggests that creativity and innovation are supported by flexible work settings, adaptable learning environments, collaborative design processes, determined effort, and liberating innovative relationships. It concludes that learning environments that seek to enable creativity and innovation should encourage collaborative working, offer flexibility for both learners and educators, enable learner-led innovative processes, and recognize that creativity occurs in curriculum areas beyond the creative arts.

\section{Introduction}

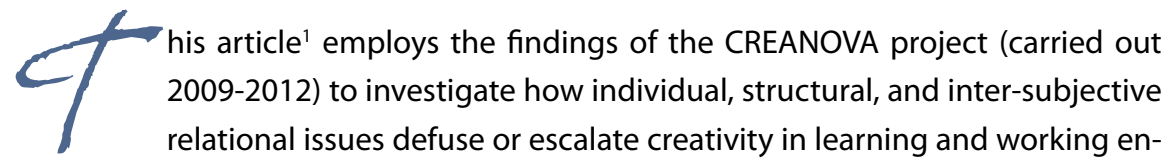
vironments; and analyzes what lessons can be learned for educationalists who seek to promote creative learning environments. CREANOVA was a major European Union (EU) research project funded by the Education, Audiovisual and Culture Executive Agency (EACEA) of the European Commission (European Commission Project Number 143725-LLP-1-2008-1-ES-KA1-KA1SCR). The project involved universities, vocational education specialists, regional governments, creative and technical experts from the Basque Country (Spain), Estonia, France, Finland, Germany, Ireland, Italy, and Scotland (UK). It investigated how learning environments, workspaces, and design 
processes were constructed to achieve sustainable innovation in the technology and creative industries.

Creativity is a "vague" and "elusive" term that has different connotations in contrasting contexts (NACCCE, 1999). Most writers suggest that creativity involves novel ideas and knowledge (Craft, 2005; Goldenberg \& Mazursky, 2002). While literatures in the past have conceptualized creativity as a solitary individual act (Saracho, 2002), there has been a recent increasing assertion that creativity is also a group activity (Sawyer, 2012; Sefton-Green, 2000).

Various writers have defined the conceptual frameworks that underpin different definitions of creativity, for example, individual, collective, emergent, and interpersonal, and have argued that our understanding of creativity and its usage is very dependent on context (Csikszentmihalyi, 1996; Misztal, 2007). In the past, creativity has been synonymously associated with artists and individuals who have changed the world through their inventions and discoveries (Sternberg, 2003). Creativity was conceptualized as an individual process, that happened only with extraordinary individuals and it was linked with divine or artistic quality that could only be delivered by very few super-intelligent or spiritual human beings (Misztal, 2007; Sawyer, 2012; Sternberg, 2003).

Changes in perception now lead us to think that creativity is also collective and it can happen through process, dialogue, brainstorming, consultation, group activity, and facilitation (Craft, 2005; Sawyer, 2012; Sternberg, 2003). This shift to a notion of creativity as a collective process raised questions for the CREANOVA project concerning what environments enabled human beings to be creative in their everyday life and what factors supported their capacity to develop and execute creative practice. It has been argued that creativity is stimulated or comes from an underlying need, e.g., economic, social, personal, technical, and so on (Sternberg, 2003). Hence, the CREANOVA project was interested in understanding the connections between collective and individual issues concerning need and environment, to identify whether there were connections between different factors that promoted creativity and innovation, and to contribute to debates that characterize creativity as an ambiguous concept (Misztal, 2007).

The CREANOVA project sought to respond to writing that had called for a more cogent analysis of creativity (Sefton-Green, 2000). It aimed to examine in more detail the environments, factors, and relationships that enabled collaborative working in systems and to pose both quantitative and qualitative questions of respondents 
concerning what a supportive creative environment looked like and how such environments worked. The project sought to carry out factor analysis to examine the comparability and interdependency among four key factors of creativity: need, freedom, environment, and social interaction. It also connected this data to qualitative data from interviews. Before proceeding to identify and discuss the results of the study this paper briefly outlines the methods employed in the study.

\section{Methods}

\section{Four sources of information and data.}

The project involved a review of international literature in the field that established our conceptual basis; an online statistical questionnaire of people in creative and technical sectors; experimental case studies that piloted innovative and creative learning tools; and qualitative interviews of key experts and creative people who had developed innovative business designs, practices, and strategies. This paper draws from the analysis of the statistical questionnaire and qualitative interviews to raise key questions about the connecting factors that influence creativity and innovation.

\section{Participants}

Twelve hundred individuals in companies in the technical and creative industries were contacted in four countries including the United Kingdom, Basque Country (Spain), Finland and Estonia to participate in an online questionnaire. A total of 507 respondents completed the questionnaire from the 1200 invitees, providing a response rate of $42.25 \%$. Among the respondents 148 worked in the public sector, 309 worked in the private sector, and 22 worked in the voluntary sector. Sixty eight respondents were male and 239 respondents were female. As well, 229 were managers or team leaders and 278 were workers or trainee workers. Participants were asked to respond by way of a five-point Likert scale to a series of questions concerning themselves, their colleagues, and their organizations and issues of creativity, innovation and learning. In order to be able to unpack the results in a more in-depth way, 45 key respondents who were identified as having led innovative processes or organizations took part in qualitative interviews in the Basque Country (Spain), Estonia, Finland, Italy, and Scotland (UK). 


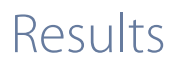

The results section briefly considers definitions of creativity and innovation before demonstrating the relationship among the four key factors: need, freedom, environment, and social interaction, however, it also demonstrates that there were gaps in the factor analysis and utilizes qualitative data to consider these gaps.

\section{Defining Creativity and Innovation}

Creativity is an ambiguous concept that is difficult to separate out from the concept of innovation, as it is a time-bound moment that brings something new into the world that may or may not be useful. The respondents to the qualitative interviews described creativity as the individual and collective ability to produce new ideas and solve problems in ways that had the potential to change the way that people engaged with objects or activities in their everyday worlds (in keeping with a range of authors, e.g., Ibáñez et al., 2010; Mumford \& Gustafson, 1998; Woodman, Sawyer \& Griffin, 1993). The findings corroborated exiting literature that suggested creativity was not only an individual endeavour, but was also collective and collaborative (Faulkner \& Coates; 2011; Sawyer, 2012). It also expanded our understanding that creative outcomes, new inventions, discoveries, ideas, and imagination can also emerge through collective processes and interactions within systems (e.g., through collective dialogue that facilitates individuals and groups to come up with new ideas or knowledge or overcome disagreements). This finding supported the work of Csikszentmihalyi (1999), who conceptualized creativity as an outcome of the interplay among a creative individual who developed new ideas and possibilities, the cultural domain which had a set of symbolic rules and procedures for receiving, preserving and transmitting novel ideas, and the field that judged, recognized, and valued the creative process. The findings supported the idea that creativity was perceived not only as an individually motivated intrinsic act, but also as an activity that thrived and emerged in individuals within the system during moments of dialogue that enabled interaction between individual impulses and external environment (Csikszentmihalyi, 1999). Yet, it also encouraged us to go beyond such writing that mainly focused on the individual (rather than groups) within the system to consider the context of collective, collaborative creative, and innovative processes.

For example, respondents in the CREANOVA project connected the concept of innovation to creativity; sometimes it was suggested that they were they same thing but at other times it was argued that innovation followed on from creative or that innovation as a process enabled creative ideas to come to fruition. People felt 
innovation allowed creativity to have practical meaning and stemmed from individuals thinking creatively, unrestricted by conventional or traditional boundaries. Innovation was described as enabling people to solve pressing problems, adapt to changing circumstances, or learn from the past. People suggested that if change processes were to occur smoothly, creativity and innovation should be inseparable from notions of design and that design was a collaborative and inter-relation process.

The findings of the CREANOVA project at first appeared confusing and contradictory, for example, when the respondents suggested creativity and innovation were the same thing or alternatively that one followed the other (Davis et al., 2011; Farrier, Quinn, Bruce, Davis, \& Bizas, 2011). However our deeper analysis suggested that it was possible to expand the definition of creativity to argue that it was any act, idea, or product that changes an existing situation. Creativity and innovation were seen as similar activities with the proviso that innovation was a process that involved creativity. These findings concurred with literature that argued creativity was the precursor to innovation, and innovation was "the successful execution of creative ideas or new product by the whole organisation" (Sawyer, 2012, p. 8).

\section{Need, Desire, Motivation, and Inspiration}

In keeping with a number of writers (Csikszentmihalyi, 1996; Misztal, 2007; Saracho, 2002; Sternberg, 2003; Sawyer, 2012), the respondents in CREANOVA project interviews argued that the desire for creativity is both external and internal and that it can be motivated by social, economic, inter-personal, technological, and communitarian factors.

Our status resulted in us choosing an innovative market strategy, unlike our rivals, to maintain market share in the higher elements of the product range. The first reason was to distinguish ourselves from the big producers, who use traditional weighing systems with load cells.

Yes, be more practical. Innovation for innovation's sake cannot be the objective. Do you get me? You have to innovate for the market. (Personal communication, respondent, Basque Country technical sector)

Internally, the urge for creativity for participants was linked with various intrinsic qualities of an individual such as imagination, self-motivation, the need to develop new skills, determination, perseverance, and so on. Externally, the thrust for creativity came from the impact of structural factors (e.g., changes in market forces, management approaches, performance review, and competition from other 
organizations, etc.) on individuals or groups and involved inter-relational issues such as the need to resolve organizational conflict.

There is an important distinction between innovation for me or for my organization which might need something totally new, never done before and have a need for novelty in the full organization (not just one department); easier, more secure and faster solutions; or more transparency (Personal communication, respondent, creative industry Estonia)

Somewhat surprisingly, the factor analysis from the online questionnaire found that creativity and innovation had no significant statistical relationship with need. We surmised that respondents had not fully understood our questions on this topic and concluded that subsequent research should consider rephrasing our needrelated questions.

The interview respondents argued that the need to be creative did not always stem from the aspiration to achieve individual gains, but also came from a wish to support others to achieve their aspirations. People stated that being and staying creative itself was one of the most challenging tasks in their job. Despite this pressure they described the challenge to create things in the learning or working environment as highly motivating.

Table 1

Factors for Creativity and Innovation, Environments, Learning, Freedom and Interaction

TESTS OF SAMPLING ADEQUACY, SPHERICITY AND VARIANCE BY FACTOR

\begin{tabular}{l|l|l|l} 
FACTOR & $\begin{array}{l}\text { KAISER- } \\
\text { MEYER-OLKIN }\end{array}$ & $\begin{array}{l}\text { BARTLETT'S } \\
\text { TEST }(P<0.05)\end{array}$ & $\begin{array}{l}\text { TOTAL VARIANCE } \\
\text { EXPLAINED }\end{array}$ \\
\hline $\begin{array}{l}\text { Environment 1: organizational } \\
\text { goals, policy, and management }\end{array}$ & .603 & .000 & $40.414 \%$ \\
\hline $\begin{array}{l}\text { Environment 2: perceived creativity } \\
\text { and innovativeness of organization } \\
\text { and colleagues }\end{array}$ & .666 & .000 & $73.970 \%$ \\
\hline $\begin{array}{l}\text { Learning 1: Training on Creativity } \\
\text { Learning 2: Training on Innovation }\end{array}$ & .815 & .000 & $76.381 \%$ \\
\hline Freedom & .667 & .000 & $76.442 \%$ \\
\hline Interaction & .826 & .000 & $45.238 \%$
\end{tabular}


Table 1 demonstrates that environment, learning, freedom, and interaction emerged from the online questionnaire as statistically significant key factors in creativity and innovation. In the interviews a number of types of work environments were found to enable creativity and innovation. For example, those that had flexible working practice, enabled cultural exchange, supported participants to put abstract ideas into practice by focusing learning processes on everyday concerns, facilitated dialogue (particularly around issues of conflict), and enabled participants to structure their own learner-led activities. It was concluded that when attempting to stimulate creativity and innovation there is a need to balance supportive organizational structures, learning opportunities, interaction between colleagues, and freedom or flexibility to attempt new things.

Environment was found to be about the relationships between people and the social structures that are constructed in organizations in terms of interaction, power-relationships, and hierarchy. Environment included the educational, economic, political, and social systems under which the conditions of innovation and creativity were forged, tolerated, accepted, rejected, or enhanced by people within social spaces (Davis et al., 2011).

Two dimensions of environment were identified: Environment 1 involving organizational characteristics (e.g., design of workspaces, organizational goals, managerial styles, policies, rules, systems, frameworks, etc.). Environment 2 involving perceived organizational creativity and innovation where individuals and groups were enabled by the organizational culture to act autonomously and collectively (e.g., individual experience of training in creativity, individual experience of training on innovation, availability of local learning spaces, worker freedom, and worker social interaction).

Qualitative findings suggested that respondents valued working together in environments that were creative, innovative, and (crucially) designed around the common good. The results implied strongly that creativity and innovation were not "individually heroic" traits. On the contrary, they could be connected to inter-relational sensitivity, gentility, generosity, caring, compassion, and recognition (Davis et al., 2011). Additionally, innovation and creativity were identified as benefiting from processes that adjusted organizational and structural conditions to allow for flexible distribution of roles, themes, and problems. These findings indicated that creativity lay in the connection and interrelationship between the individual and the environment. Indeed, Table 2 demonstrates the correlation scores among the various factors. 
Table 2

Correlation Among Factors

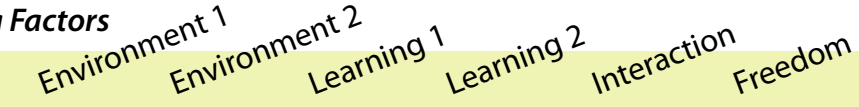

\begin{tabular}{l|l|l|l|l|l|l|} 
Environment 1 & - & 0.24 & 0.13 & - & 0.28 & - \\
\hline Environment 2 & 0.24 & - & 0.36 & 0.32 & 0.56 & 0.46 \\
\hline Learning 1 & 0.13 & 0.36 & - & 0.80 & 0.35 & 0.20 \\
\hline Learning: 2 & - & 0.32 & 0.80 & - & 0.32 & 0.12 \\
\hline Freedom & 0.28 & 0.56 & 0.35 & 0.32 & - & 0.39 \\
\hline Interaction & - & 0.46 & 0.20 & 0.12 & 0.39 & - \\
\hline
\end{tabular}

The correlation scores in the table above illustrate the complex web of interrelationships among factors. Most factors were interrelated with the exception of the Environment 1 organizational structure which was not correlated with freedom or learning on innovation. This suggests that some factors co-exist without influencing each other.

\section{Diversity, Freedom, and Interaction-A Condition for Innovation}

Respondents to the survey and interviews highlighted the need for diversity and tolerance as a condition for innovation. They suggested that innovation flourished in settings where staff were enabled to challenge traditional approaches, welcome difference, contest hierarchies, experience openness, feel respected, and avoid sanctions for mistakes. Respondents also highly valued work environments that were free from time-pressure anxiety and enabled risk taking, tolerance of ambiguity, autonomy, reflection, self-directed working, and the promotion of high degrees of initiative.

When linear regression was run with all the independent variables in our survey data, very encouraging results were produced. The multiple correlation coefficient $\left(R=0.629^{\mathrm{a}}\right)$, which looked at the association of all the variables together, including environment, training, interaction freedom, and so forth, showed that the variables were highly correlated and that they predict creativity and innovation in environments very well. The R Square $(R$ Square $=0.396)$ meant that roughly $39.6 \%$ of the variance in creativity and innovation in environments could be explained by the combination of training, interaction, and freedom, a very good percentage. 
Correlations among factors are given in Table 2 that illuminate the relationships between the dependent variable and the influence of the independent variables.

Our ANOVA significance test showed that the model was statistically significant and appropriate. Additionally, our coefficient table showed us that the independent variables positively affect creativity and innovation in environments (e.g., the higher the social interaction in an environment, the more creativity and innovation identified in it). As seen in Figure 1, all factors that correlate do so positively. So, for example, the more freedom there exists in an environment, the more creativity and innovation is identified in it and the more social interaction. The same was found for social interaction, which had the strongest correlation with creativity and innovation.

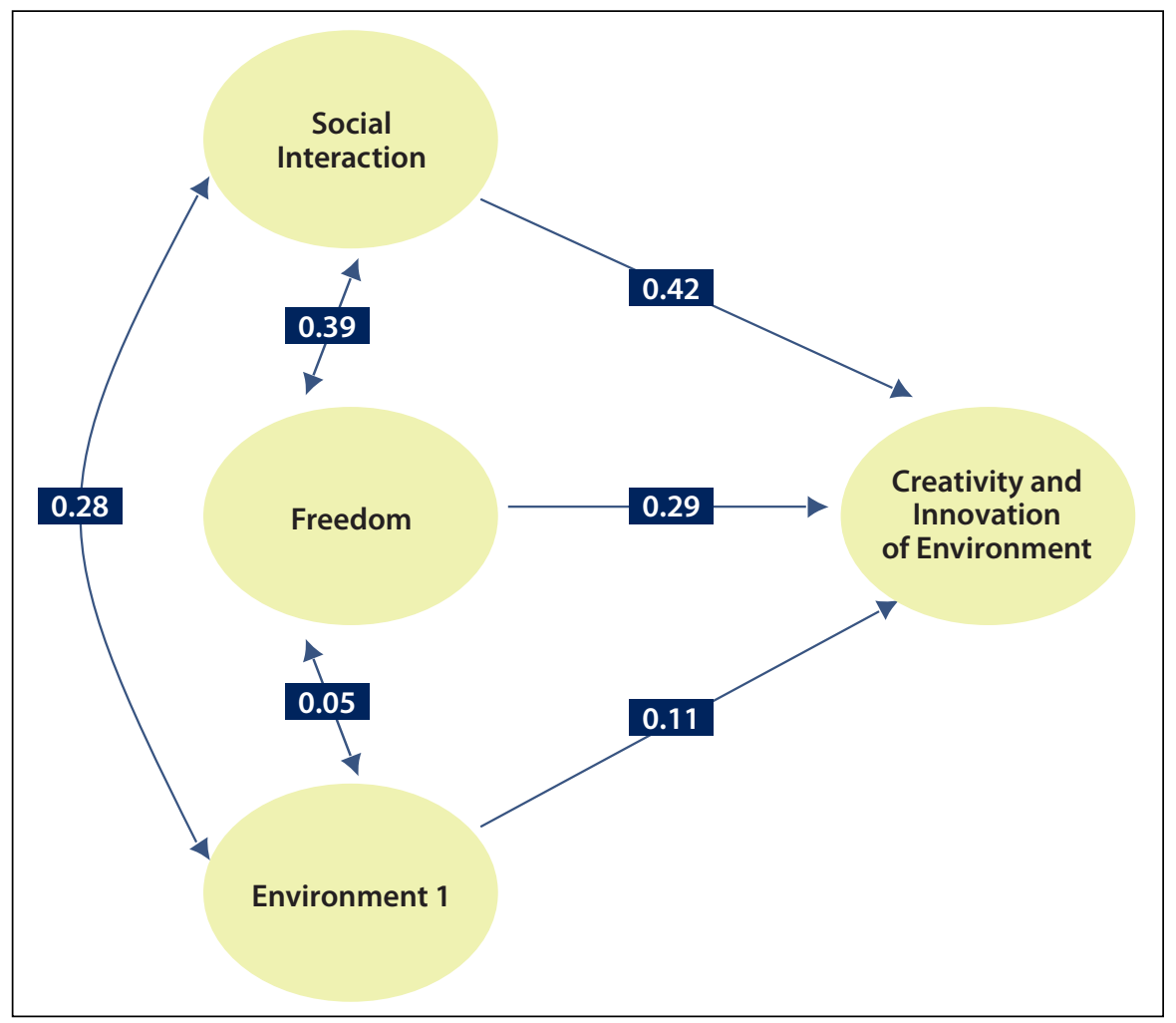

Fig. 1: Influence of 3 factors on creativity and innovation of environment

However, Environment 1 correlated weakly on its own with creativity and innovation and had a non-significant correlation with freedom. Figure 2 illustrates the correlation relationships among the factors after we have removed environment. 


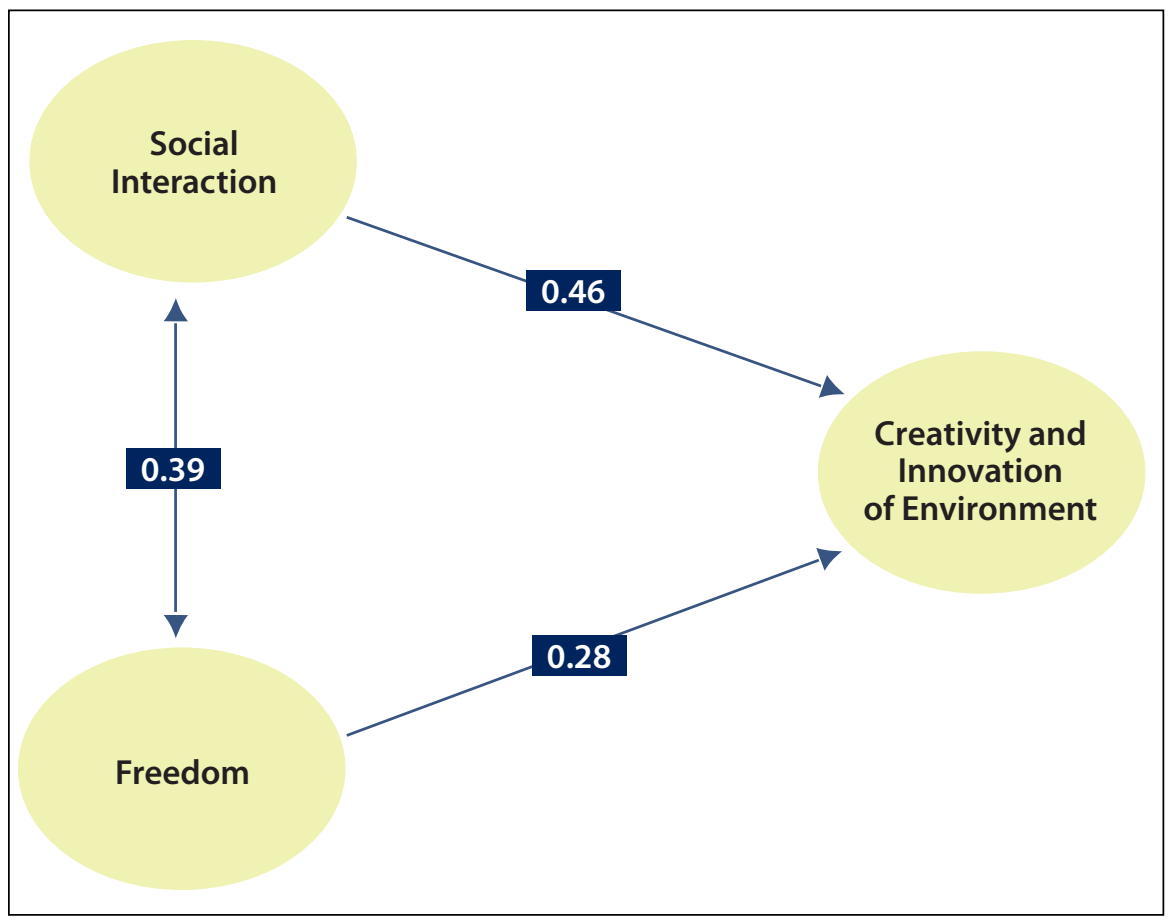

Fig. 2: Influence of two factors on creativity and innovation of environment

When connected to interview and case study data, this suggested that flexible frameworks were more necessary factors than total individual freedom for creativity and innovation. Hence, collaboration seemed more important than individual freedom, that is respondents perceived that, the stronger the social interaction there was in an environment (e.g., the more workers shared the same values, humour influenced their work place, issues of equality and diversity were valued in the workplace); and the more freedom there was (the more people were autonomous to make choices, use personal initiative, etc.), then the more creative and innovative were the environments. This suggested that the inter-relational context within which people are located plays an important part in creativity and innovation. It was possible to conclude that the skill, knowledge, values and experience of a person is not enough to stimulate creativity if the spaces that learners/workers live in are so formally structured or limited that they do not meet people's aspirations to practically utilize their creative potentials (Farrier et al., 2011). In particular, it was argued in qualitative interviews that companies would be wasting money on training on innovation and creativity if the contexts within which people worked did not enable them to be free to interact with others to put into practice what they had learnt from the training. 
To innovate, a tradition of innovating must be deeply rooted in all segments of the company. It must be a constant in all areas, from human relations to sales representatives, production and management staff. They must be capable of defending their area, overcoming quarrels, jealousy and in-company struggles. An innovation culture must exist. (Personal communication, respondent, Creative industry, The Basque Country)

These findings support the work of writers that critique top-down management ideas that assume, for instance, that workers needed extrinsic rewards and monitoring (Seddon, 2008). Our study results substantiated other literature that has argued that creativity and innovation can be hindered or crushed by rigid hierarchy, simplification, uniformity and control associated with traditional industrial and school systems (Sawyer, 2012).

On a whole, the environment was seen as an important factor for facilitating creativity and innovation. The CREANOVA project was able to clarify the different aspects of "environment" that supported change (e.g., mentoring, flexible rules, relevant working agreements, technology, well-designed working spaces, teamwork, etc.).

The qualitative findings were also able to suggest other factors that might explain the gaps in the factor analysis; for example, during interviews respondents emphasized the importance of design, planning, and "stick-ability." Stick-ability was defined as "staying the course" and seeing plans or agreements through to the end. Respondents suggested that a combination of individual and structural factors pushed individuals and groups to stay focused, positive, and creative.

It requires a long-term commitment, one shouldn't give up after the first or fifth failure. People are not the same; not everyone is a developer; some people even suffer from too much freedom. We also need people who are more monotonic and repetitive. (Personal communication, respondent, Finland technical industry)

I suppose creativity is the resource that you have that you can draw on, which then goes in through a design process, and leads you to an innovation. So design is like the glue, we call it the glue between creativity and innovation, so creativity doesn't necessarily have to have a purposeful output and innovation is a new way of doing things and a new way of approaching things, but it has a practical implication and the design process is what links the two of them. (Personal communication, respondent, creative industry, Scotland) 
In this way, design (or structure) was identified as a bridge (or the glue) between creativity and innovation. This also suggested that it was as important for people to learn about how to plan innovative processes that enabled them to deliver creative outcomes so as to learn about how to be creative. The final discussion section of the paper connects such findings to literature on learning, innovation, and creativity. The CREANOVA respondents particularly stated that creativity and innovation benefited from collaborative, multi-professional and cross-cultural learning and the final section considers this finding in relation to work-related learning and to children's learning.

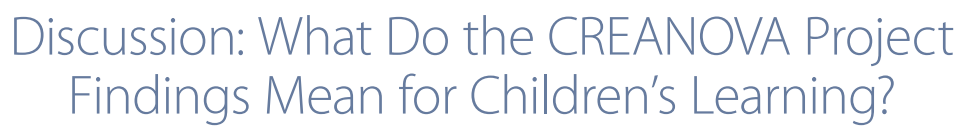

Participants in the CREANOVA project viewed learning and working contexts as crucial to creativity and innovation. This enabled us to reject traditional behaviourist models of learning that have suggested that people learn from repetition, reinforcement, reward, and punishment (Laird, 1985). In schools these ideas have been challenged by the constructivist idea that learning should enable the learner to analyze, conceptualize, and synthesize their prior experience into new knowledge, and that the teacher or instructor should reflectively facilitate the learning environment when trying to transmit knowledge (Dahlberg, Moss, \& Pence, 1999; Popkewitz \& Bloch, 2001). Such ideas suggested children required a certain degree of freedom to be involved with the activity of their choice, but at the same time they also argued that children needed a mentor or facilitator for guidance (Foster, 1971). It is argued that creativity itself is a challenging task, it demands certain skills, and that these skills have to be learnt or nurtured in childhood through training or education. Yet, the preponderance in schools of romantic models of creativity that believed creative individuals are born, not made, offer little room for adult-led nurturing of creativity and also ignored the role of peer group interaction (Sefton-Green, 2000). The CREANOVA project findings bring into question writing that places emphasis on the liberal concept of individual success stimulated by individual teacher-child interaction and suggests that we should reengage with the concept of peer and collaborative learning. Collectivist notions of creativity identified in the CREANOVA project can more easily be connected with writing that highlights the need for flexibility when considering the emerging nature of creative ideas in childhood (Sawyer, 2012). More contemporary writing has connected the idea of individual reflection to group approaches to reflexive learning that highlight the connections among experience, 
environment, flat hierarchies, learning, sharing, and reflection. Such writing promotes the idea that change can be stimulated by collective dialogue of everyday problems (Davis \& Smith, 2012; Dewey, 1938; Turnbull, 2009), that learning embedded in an emergent activity can enable a qualitative transformation of the entire activity system (Davis et al., 2011; Davis \& Smith, 2012; Engeström, 2004), and that there is a strong relationship among learning pedagogies, the construction of children in the curriculum, and creativity (Craft, 2005; Foster, 1971).

Learning pedagogies shape learning environments, both formal ones that are envisaged overtly in educational curriculum documents and informal ones that are underpinned in adult-child interaction (Craft, 2005; Moyles, 2010a). It is not clear that those trying to promote creative learning in schools are able to always utilize flexible approaches to learning that enable children to learn collaboratively. Indeed, arts and media topics are introduced in the curriculum because they are believed to be the subjects best suited to nurturing creativity in children. Yet this leads many teachers to fail to associate creativity with processes inherent in arts-based curriculumfor example, teachers may well overlook the creative planning and design aspects of more science-based topics (Sefton-Green, 2000). There has often been discontinuity in the way creativity is embedded in different curricula. It has been argued that the focus of the curriculum is often on art activities rather than cross-curricular skills and life skills (Craft, 2005). For example, teachers sometimes ignore the suggestions that creativity can be connected to the whole curriculum and disregard the principle that creativity is important not only for visual arts, but it is also relevant in other aspects of learning -in peer interaction, in problem solving, in language socialization, and so on (Craft, 2011).

The CREANOVA project findings suggest that schools who utilize interactive approaches to learning may enable children to develop creative planning, resilience, and "stick-ability" skills that will be very useful in future creative workplaces. The project findings also suggested that a focus on joint problem solving in schools might better enable children to identify with collective and less hierarchical notions of creativity. The CREANOVA project enabled us to conclude that learning environments that seek to promote creativity and innovation should interactively enable and stimulate the impulses, interest, intentions, and actions of the learner (Davis \& Smith, 2012). This finding raises questions about how effective we are at promoting learning on creativity and innovation in ways that enable people to learn about innovation as a process. The findings also encourage us to pose questions concerning how effective we are at helping children learn how to plan and develop processes of innovation that enable creative ideas to come to fruition or learners to experience and 
overcome uncertainty and discontinuity. We concluded, as others have, that there is an inherent tension in how creativity is pronounced in policy documents and how it is translated into practice in learning environments (Burnard \& White, 2008; Craft, 2005; Moyles, 2010a). Although creative agendas are expressed in policy documents, for example, that articulate the need for creative education in schools and emphasize freedom and empowerment, educational practices are bureaucratized through central administration and control regimes and school authorities are pressured to comply with standards through performativity (Burnard \& White, 2008).

The CREANOVA findings also raise questions about what approaches stimulate collaborative creativity in childhood. Playful pedagogies are strongly advocated as a means to achieve creativity in childhood, particularly in the early years. Play can be viewed as "spontaneous and joyful, stylised and regulated, revealing imbalances of power and social hierarchy and also as blurring the boundaries of the real and imaginary" (Montgomery, 2009, p. 143). It is postulated that play is a most natural activity that happens in children's lives across all cultures, that play is universal, and that all children have a natural tendency and inclination towards play (Moyles, 2010b). Papatheodorou (2010) argues playful learning environments provide a pedagogy that supports creative activity, forges strong interaction, enables communication with others, provides opportunity for cooperation, encourages joint problem solving, promotes independence, and enables interdependence.

In reality, at-home play is yet not wholeheartedly accepted among parents; in schools, the concept of teaching as a formal activity reduces opportunities for flexible learning and the value of play in terms of its contribution to "actual" learning is not clearly explicated and understood by parents and teachers (Moyles, 2010a). Indeed, the notion that play activities automatically enable creativity is simplistic and overlooks writing that argues that children often encounter barriers to play such as the inability to interact outdoors free of adults or a preponderance of overtly adultcontrolled learning spaces in schools (Moyles, 2010a). The CREANOVA findings suggest that learners have to be able to put into practice their learning in flexible and supportive environments. The project findings suggest there may be a tension between adult- and child-led processes and that a tendency towards adult-structured learning in schools might act to prevent the development of children's creativity and innovation. All too often children's play is "overseen" by adult "facilitators" in ways that seem contradictory to the findings of the CREANOVA project.

The CREANOVA project findings suggest that people can be encouraged to be creative and innovative if the spaces they work in value diversity and enable 
them to try out new ideas. This brings into question the ideas of those who promote more controlled and adult-led approaches to children's play. For example, Duffy (2006) views creativity and imagination through a developmental lens. This way of seeing creativity suggests certain limits to creativity, (i.e., predictability of creative experiences linked to age and stage of the child). Children are positioned as inferior to adults and adults are promoted as necessary guides of the creative process. The influence of child development theories and the introduction of Developmentally Appropriate Practices (DAP) into early childhood fields across the world has made an impression that child development is universal and it happens at the same pace and level to every child (Papatheodorou, 2010).

Woodhead (2009) has encouraged us to reject crude versions of learning and developmentalism that are based on rigid hierarchies and to engage with more contemporary approaches to development that are concerned with connections among physical, relational and cultural factors that influence changes in children's growth, learning, and well-being. In childhood studies, there has been an overwhelming response among scholars that see children as active agents of their social world (James, Jenks, \& Prout, 1998; Mayall, 2002), thus, any theory which talks about creativity in learning environments should take into consideration the idea that children are the chief constructors in the creative process and they are instrumental in the meaning-making process of everyday creative activity (Faulkner \& Coates, 2011; Moyles, 2010a).

Yet, post-structuralist thinkers have moved even beyond the child agency/ adult structures debate to argue in a similar way to the CREANOVA project that freedom and structure can co-exist and support creativity in the same social spaces. Gilles Deleuze (1925-95) and Felix Guattari (1930-92) have viewed the concept of creativity as in-between movements and flows, rather than outcomes of play. Deleuze and Guattari "did not see the impossibility of organising life around closed structures as problematic. Instead, they saw this as an opportunity to experiment with, invent and create different ways of knowing" (Brooker \& Edwards, 2010, p. 86).

Though learning takes place while they are playing, children's intention is not always to play in order to learn (Kalliala, 2006). Similarly, play in early years is not always fun and innocent; it can also be political and may have ethical and moral implications (e.g., it can be gendered and involve discrimination) (Grieshaber \& McArdle, 2010). In a similar way to the CREANOVA project findings it has been argued that the socio-cultural environment is important for the child to realize his/her agency in play-based learning (Bruce, 2010). Spontaneous, free-flow "divergent thinking" has 
been viewed as instrumental for play and creativity in the early years (Sylva, Bruner, \& Jolly, 1976), but creativity has also been connected with a combination of divergent and convergent thinking in "possibility thinking" which promotes risk, consideration of alternatives, imagination of new ideas, and posing of questions (Craft, 2000, 2011). Such writing has sought to encourage children's abilities with regards to imagination, exploration, decision making, and problem solving. It has encouraged teachers to develop enabling contexts, by centring themselves off-stage and utilizing flexible pedagogy that enable children to foster their autonomy by taking space and time to develop ownership of their own discovery-type learning. We can see connections between writing that encourage teachers to work in flexible ways and ideas identified in the CREANOVA project concerning freedom, interaction, and the need for flexible forms of support.

The proliferation of post-modernist approaches to learning has recognized the ability of the learner to make choices/meanings and therefore make alternative constructions of the knowledge of the teacher (Dahlberg et al., 1999). The CREANOVA project findings suggest that such skills will be extremely useful in the creative work places of the future. However, it should be noted that in Childhood Studies such approaches are promoted because they support children to express their identities in the present rather than because they might help with a forthcoming need to be productive adults in the future (Lorenz \& Lundvall, 2011; Sawyer, 2006).

The CREANOVA project findings point to the need for learning frameworks and relationships as well as flexibility and freedom. They emphasize the importance of learner-led collaborative knowledge production. The concept of learner-led creativity encourages us to be cautious in our aim to enable children's creativity, for example, it suggests that those who seek to simulate a shift in thinking and practice on creativity and innovation in early years settings and schools should encourage teachers to avoid assuming that any single activity automatically stimulates creativity. The CREANOVA project findings also suggest that it will be important for adults planning creative activities to: negotiate with children; build on children's aspirations; be clear about freedoms and constraints; agree on specific shared objectives or success criteria; and allow for discussion, debriefs, feedback. Moreover, the CREANOVA project findings suggest that learning activities benefit from having a focus (e.g., on a shared problem) yet also need to be flexible enough to enable participants to set the direction of travel, can be connected to writing that has argued we need to reconsider constructivist approaches to children's learning, and overcome paradigm divides and disciplinary boundaries in relation to childhood creativity (Faulkner \& Coates, 2011; Sawyer, 1999, 2006, 2012). Such writing has promoted a "collaborative 
emergence theory" of collective and complex creativity and has argued that emergent processes are not only cognitive they are also occur as a bottom-up process in systems that involve constant improvisation by their creators (Faulkner \& Coates, 2011). For example, Faulkner and Coates (2011) decontextualized the notion of agerelated development and creativity in developmental psychology and asserted that children's creative narratives are collaborative, improvisational, and contextual.

While literature in the past supported either "learner agency" or "teacher agency," we propose that the mediation between these two and a flexible learning environment is mandatory for fostering creativity. Faulkner and Coates (2011) suggest children's creative narratives are co-constructed with their peers or teachers in learning environments and they emerge mainly in collaborative processes. This is similar to other work that has argued that learning environments that promote creativity and innovation should involve supportive frameworks that mediate learner-teacher agency, value cross-curriculum learning, recognize collective strength in knowledge production, and balance ideas of autonomy, diversity, and co-option (Popkewitz \& Bloch, 2001).

Discourses on children's creativity that hitherto were dominated by individual, cognition-based psychological theories, thus, are now beginning to take into account the social and political processes involved in everyday creativity. Moreover, our research supports the contention that we need to better understand how children's interpretations of creative processes and their creative outputs change over time and further examine the nature of their "progressive continuous recontextualisation" of creativity (Faulkner \& Coates, 2011, p. 2). Therefore, it is our conclusion that educational settings that seek to promote creativity will benefit from considering how they can better become spaces where children carry out learner-led collaborative knowledge production and spaces where children are enabled to situate learning in their everyday life contexts.

\section{Conclusion}

Creativity and innovation are enabled by environments that engage with diversity, celebrate complexity, and value collaboration. IWe have argued that rather than silencing creativity (e.g., through the imposition of a rigid, strict, universal pedagogy), we should create enabling environments that recognize children's and adult's creative potential and employ flexible frameworks to support that potential 
to flourish. At the centre of this argument is the idea that creativity is not a gift that powerful managers or teachers should give to workers or pupils. Creativity is something that can be achieved by us all and can flourish in social spaces where people are enabled individually and collectively to achieve their aspirations. Creativity is individual, collective, emergent, and interpersonal; it stems from internal and external sources of inspiration and is motivated as much by communitarian as individual goals. This paper promotes the idea that creativity and innovation benefit from collaborative leadership and inter-personal/interactive design processes that enable issues of conflict to be worked through in teams. It has set out the key environmental issues that support the development of creativity and innovation including design of workspaces, organizational goals, managerial styles, policies, rules, systems, frameworks, training/learning spaces, worker freedom, worker social interaction, and so on. It has encouraged readers to consider what sensitive learner-led approaches to creativity and innovation might look like for adults and children. We would finally like to conclude that our work suggests that educationalists need to move beyond rigid individualist, constructivist and child development notions of learning to more interactive, flexible, and complex positions. Indeed, the creativity of the CREANOVA project itself stemmed from the collaboration across countries of a diverse group of researchers and it stands as an example of what can be achieved when people from different cultures collaborate, explore and joint problem solve in ways that don't assume there is one universal approach to learning or working.

\section{Note}

1. This research was supported by the European Commission's Education, Audiovisual and Culture Executive Agency (EACEA) Grant 143725-LLP-1-2008-1-ES-KA1KA1SCR. Professor John M. Davis led the research analysis work package on this project. Correspondence concerning this article should be addressed to Professor John M. Davis, The Moray House School of Education, The University of Edinburgh, Charteris Land, Holyrood Road, Edinburgh EH8 8AQ. Email: john.davis@ ed.ac.uk 


\section{References}

Brooker, L., \& Edwards, S. (2010). Engaging play. Maidenhead: McGraw Hill Open University Press.

Bruce, T. (2010). Play, the universe and everything. In J. Moyles (Ed.), The excellence of play (3rd ed.). Berkshire: Open University Press.

Burnard, P., \& White, J. (2008). Creativity and performativity: Counterpoints in British and Australian education. British Educational Research Journal, 34, 667-682.

Craft, A. (2000). Creativity across the curriculum: Framing and developing practice. London: Routledge.

Craft, A. (2005). Creativity in schools: Tensions and dilemmas. London: Routledge.

Craft, A. (2011). Creativity and early years setting. In A. Paige-Smith \& A. Craft (Eds.), Developing reflective practice in the early years (2nd ed.). Berkshire: Open University Press.

Csikszentmihalyi, M. (1996). Creativity: flow and the psychology of discovery and invention. New York: Harper Perennial/Harvard Business School Press.

Csikszentmihalyi, M. (1999). Implications of a systems perspective for the study of creativity. In R. J. Sternberg (Ed.), Handbook of creativity. Cambridge: Cambridge University Press.

Dahlberg, G., Moss, P., \& Pence, A. (1999). Beyond quality in early childhood education and care: languages of evaluation. London: Routledge.

Davis, J. M., Bizas, N., Farrier, S., Bruce, A., Petrasch, C., \& Lange, M. (2011). Embedding vision: final report of the CREANOVA project. Edinburgh: Edinburgh University Press. A project funded by the Education, Audiovisual and Culture Executive Agency (EACEA) of the European Commission, Project No. 143725-LLP-1-2008-1-ES-KA1-KA1SCR.

Davis, J. M., \& Smith, M. (2012). Working in multiprofessional contexts: A practical guide for professionals in children's services. London: Sage.
Dewey, J. (1938). Experience and education. New York: Collier Books.

Duffy, B. (2006). Supporting creativity and imagination in the early years (2nd ed.). Berkshire: Open University Press.

Engeström, Y. (2004). Managing as argumentative history-making. In R. Boland (Ed.), Managing As Designing. Stanford University Press. Eisentein, E. Stanford.

Farrier, S., Quinn, K., Bruce, A., Davis, J. M., \& Bizas, N. (2011). Supporting ICT situated learning and virtual skills rehearsal in workforce development. Paper presented at the European Distance and E-Learning Network (EDEN) annual conference, June, Dublin.

Faulkner, D., \& Coates, E. (2011). Exploring children's creative narratives: some theoretical, methodological and applied perspectives. In D. Faulkner \& E. Coates (Eds.), Exploring Children's Creative Narratives. London: Routledge.

Foster, J. (1971). Creativity and the teacher. Basingstoke: Macmillan.

Goldenberg, J., \& Mazursky, D. (2002). Creativity in product innovation. Cambridge: Cambridge University Press.

Grieshaber, S., \& McArdle, F. (2010). The trouble with play. Berkshire: Open University Press.

Ibanez, J., Fernandez, I., Arandia, M., Eizagirre, A., Barandiaran, M., Etxebarria, I. et al. (2010). Discovering vision: theoretical foundations and practical solutions in the field of creative learning, Report from the creative learning networking for European innovation, A project funded by the Education, Audiovisual and Culture Executive Agency (EACEA) of the European Commission, Project No. 143725-LLP-1-2008-1-ES-KA1-KA1SCR.

James, A., Jenks, C., \& Prout, A. (1998). Theorizing childhood. Cambridge: Polity Press.

Kalliala, M. (2006). Play culture in a changing world. Berkshire: Open University Press.

Laird,D. (1985). Approaches to training and development. Reading, MA: Addison-Wesley. 
Lorenz, E., \& Lundvall, B. (2011). Accounting for creativity in the European Union: A multilevel analysis of individual competence, labour market structure, and systems of education and training. Cambridge Journal of Economics, 35, 269-294.

Mayall, B. (2002). Towards a sociology for childhood: Thinking from children's lives. Buckingham: Open University Press.

Misztal, B.A. (2007). Intellectuals and the public good: creativity and civil courage. Cambridge: Cambridge University Press.

Montgomery, H. (2009). An introduction to childhood: anthropological perspectives on children's lives. Sussex: Wiley-Blackwell.

Moyles, J. (2010a). Introduction. In J. Moyles (Ed.), The excellence of play (3rd ed.). Berkshire: Open University Press.

Moyles, J. (2010b). Introduction. In J. Moyles (Ed.), Thinking about play: Developing a reflective approach. Berkshire: Open University Press.

Mumford, M.D., \& Gustafson, S. (1998). Creativity syndrome: Integration, application and innovation. Psychological Bulletin, 103, 27-43.

National Advisory Committee on Creative and Cultural Education (NACCCE). (1999). All our futures: Creativity, culture and education. London: Department for Education and Employment.

Papatheodorou, T. (2010). The pedagogy of play(ful) learning environments. In J. Moyles (Ed.), Thinking about play: Developing a reflective approach. Berkshire: Open University Press.

Popkewitz, T.S., \& Bloch, M.N. (2001). Administering freedom: A history of the present - rescuing the parent to rescue the child for society. In Hultqvist, K., \& Dahlberg, G. (Eds.), Governing the child in the new millennium. London: Routledge Falmer.
Saracho, O. (2002). Young children's creativity and pretend play. Early Child Development and Care, 172, 431-438

Sawyer, R. K. (1999). The emergence of creativity. Philosophical Psychology, 12, 447-469.

Sawyer, R. K. (2006). Education for innovation. Thinking Skills and Creativity, 1, 41-48.

Sawyer, R. K. (2012). The science of human innovation: Explaining creativity (2nd ed.). Oxford: Oxford University Press.

Seddon, J. (2008). Systems thinking in the public sector: The failure of the reform regime - $a$ manifesto for a better way. Axminster: Triarchy Press.

Sefton-Green, J. (2000). Introduction - Evaluating creativity. In J. Sefton-Green \& R. Sinker (Eds.), Evaluating creativity: making and learning by young people, London: Routledge.

Sternberg, R. J. (2003). Wisdom, intelligence, and creativity synthesized. Cambridge: Cambridge University Press.

Sylva, K., Bruner, J., \& Jolly, A. (1976). Play, its role in development and evolution. Harmondsworth: Penguin.

Turnbull, A. (2009). Using line management. Melbourne: School of Education.

Woodhead, M. (2009). Child development and the development of childhood. In J. Qvortrup, Corsaro, W. A., \& Honig, M. S. (Eds.), The Palgrave handbook of childhood studies. London: Palgrave.

Woodman, R. W., Sawyer, J. E., \& Griffin, R. W. (1993). Toward a theory of organisational creativity. Academy of Management Review, 18, 293-321 


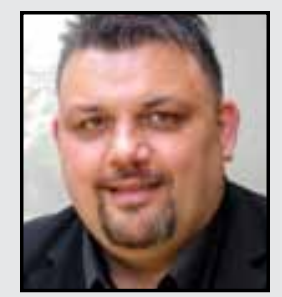

John M. Davis is Professor in Childhood Inclusion at the University of Edinburgh. His research has critically examined participatory research methods and focused on understanding children's and professional's perspectives of inclusion, social justice, and multi-professional working. He has extensive experience in developing creative and innovative professional development resources and his major concern has been to develop contemporary examples of inclusion that children, families, and professionals can utilize to change children's services. He has a BSC (Hons) Social Anthropology and Sociology from the University of Ulster at Coleraine and a PhD in Education from the University of Edinburgh.

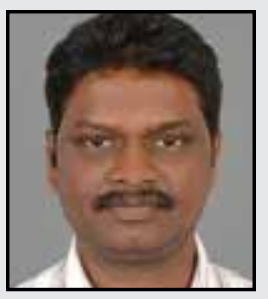

Vinnarasan Aruldoss is a PhD student in Social Policy at Edinburgh University researching children's and families' experiences of early years services in India. He is also an associate tutor on "Social Policy and Society" and "the Politics of the Welfare States" for the undergraduate courses in Social Policy at Edinburgh University. Previously, he worked for several years as a lead practitioner in India on projects with local Non-Governmental Organizations, Governmental Research Organizations, Medecins Sans Frontieres and the United Nations Development Programme. He holds a Bachelor's degree in Statistics and a Master's degree in Social Work from Madras University, India. 


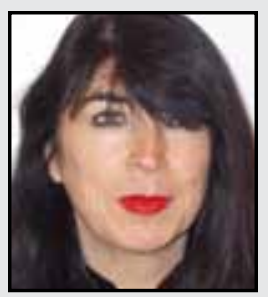

Lynn McNair is Head of Centre in a leading Early Childhood Education setting. Lynn has over thirty years experience working with young children and their families. Lynn is an associate tutor on the B.A. in Childhood Practice and the Froebel in Childhood Practice professional development course at the University of Edinburgh. Lynn is a leader in early years professional development and collaborates with the Scottish Government and other bodies. Lynn is an award-winning author, has a Masters in Early Education from Strathclyde University, and is currently working on a PhD at the University of Edinburgh.

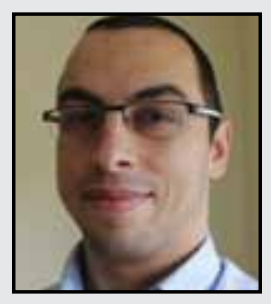

Nikolaos Bizas is a researcher whose work focuses on international comparative research in education, learning, and social policy issues. He is currently working for the University of Edinburgh and is involved in planning, developing, and coordinating a number of EU-focused research projects. Nikolaos has also worked with leading organizations in Scotland including the Scottish Social Services Council, Voluntary Health Scotland, and think tanks such as the Centre for Scottish Public Policy. He holds a BSc in Sociology from the University of Crete and an MSc in International and European Politics from the University of Edinburgh. 